\title{
Letters
}

\section{Gerald Caplan, then and now: public mental health applications to the current psychological challenges of the pandemic}

Mental health providers are struggling to meet the "surge on surge" pandemic demands for services, especially for the pediatric population. Mental health reactions to the pandemic range from adjustment reactions to its impact on the individual, or his or her social network, to exacerbation of pre-existing psychological problems. An overall strategy for managing and preventing mental health problems from developing is lacking.

Five decades ago, psychiatrist Gerald Caplan proposed a public health preventive model for mental disorders, applied at the population level. Although shunned by mainstream psychiatry, his ideas were embraced by schools, organizations and communities. In addition to addressing the issue of access, Caplan showed how community approaches challenge the traditional paradigm of individual clinic and office delivery of psychological services.

Over the next 2 decades, Caplan laid the foundation for school, community and organizational psychology, including shifting focus from the individual to the systems level, applying primary, secondary and tertiary prevention methods to sustain mental health, shifting the role of the consultant to that of a facilitator for individual consultees or organizations to solve their work problem, outlining the need to understand mental disorders in the context of the whole institution, organization or culture, introducing brief methods of intervention and formulating social support theory as a means of dealing with crises. ${ }^{1}$

Subsequent evidence has supported his approach. Early intervention services have the greatest and most longstanding impact than any other form of service delivery by increasing the educational readiness of students at risk of mental distress, developing the interpersonal and social problem-solving competence of children with social skill deficits, training parents to respond to their children's physical, emotional and developmental needs, decreasing child abuse and responding to individual and community-wide crises. Even so, policymakers have ignored these outcomes in favour of preserving managerial or private practice systems that do little to enhance population-level standards for mental health. ${ }^{2}$

Ironically, the pandemic has resulted in the increased use of teleconferencing and virtual platforms that actually extend the reach of mental health consultants across time and physical space, and enhanced their collaborative opportunities with parents and educators, important aspects of Caplan's approach. As the public demands more access to mental health services, and politicians and policy-makers debate the most efficient ways to accomplish this, Caplan's views are relevant now more than ever. They would help us respond to pandemic-specific mental health concerns and, in the process, reshape how we, as a society, think about prevention and mental health for everyone.

\section{Normand J. Carrey MD}

Associate professor, Dalhousie University; Department of Child and Adolescent Psychiatry, IWK Health Center, Halifax, NS

Cite as: CMAJ 2021 October 25;193: E1635. doi: 10.1503/cmaj.80232

\section{References}

1. Erchul WP, editor. Consultation in community, school, and organizational practice. New York: Taylor \& Francis; 2015

2. Knoff H, Batsche G. A school reform process for at-risk students: applying Caplan's organizational consultation principles to guide prevention, intervention, and home-school collaboration. In: Erchul WP, editor. Consultation in community, school, and organizational practice. New York: Taylor \& Francis; 2015:125.

Competing interests: None declared.

Content licence: This is an Open Access article distributed in accordance with the terms of the Creative Commons Attribution (CC BY-NC-ND 4.0) licence, which permits use, distribution and reproduction in any medium, provided that the original publication is properly cited, the use is noncommercial (i.e., research or educational use), and no modifications or adaptations are made. See: https://creativecommons.org/ licenses/by-nc-nd/4.0/ 